\title{
Delayed Tension Pneumocephalus Following Intraoperative Cerebrospinal Fluid Leakage Repair
}

\author{
Joon Yong Park ${ }^{(D}$, Hansol Kim (D), Taesik Jung ${ }^{(D)}$, and Jin Kook Kim (D) \\ Department of Otorhinolaryngology-Head and Neck Surgery, School of Medicine, Konkuk University, Seoul, Korea \\ 뇌척수액 비루의 내시경적 치료 후 발생한 지연성 긴장성 뇌기종 1 예 \\ 박준용 · 김한솔 · 정태식 · 김진국 \\ 건국대학교 의학전문대학원 이비인후-두경부외과학교실
}

\author{
Received August 25, 2020 \\ Revised November 23, 2020 \\ Accepted December 18, 2020 \\ Address for correspondence \\ Jin Kook Kim, MD, PhD \\ Department of Otorhinolaryngology- \\ Head and Neck Surgery, \\ School of Medicine, \\ Konkuk Unversity, \\ 120-1 Neungdong-ro, Gwangjin-gu, \\ Seoul 05030, Korea \\ Tel $+82-2-2030-7662$ \\ Fax $+82-2-2030-5299$ \\ E-mail entalk@kuh.ac.kr
}

Tension pneumocephalus is a rare complication of endoscopic sinus surgery (ESS) that may lead to rapid neurologic deterioration. Symptoms typically develop within the first postoperative week after enough air has entered the intracranial cavity to create pressure on the dura. Furthermore, there may be a rapid onset of symptoms after a positive pressure event. However, there may be a more insidious onset of symptoms in the absence of a positive pressure event. We report a rare case of delayed tension pneumocephalus following an intraoperative cerebrospinal fluid leak repair. We discuss here the mechanisms of this complication and the diagnosis and treatment strategies of tension pneumocephalus after an ESS.

Korean J Otorhinolaryngol-Head Neck Surg 2021;64(11):820-4

Keywords Cerebrospinal fluid leak; Inverted papilloma;

Natural orifice endoscopic surgery; Tension pneumocephalus.

\section{Introduction}

Intracranial complications of endoscopic sinus surgery (ESS) are very rare, occurring in less than $1 \%$ of cases. ${ }^{1 .}$ The complications of ESS include cerebrospinal fluid (CSF) leak, ${ }^{1,2)}$ meningitis and pneumocephalus, which are more common. Pneumocephalus is the presence of air in the cranial cavity, and it usually resolves spontaneously and is asymptomatic. When the amount of air in the cranial cavity is increased due to coughing, sneezing, and vomiting during the postoperative period, neurological symptoms occur due to the mass effect. This condition is called tension pneumocephalus. ${ }^{3)}$ Clinical presentation of tension pneumocephalus includes headache, nausea, vomiting, seizures, dizziness, and neurological deficits. ${ }^{4,5}$

This is an Open Access article distributed under the terms of the Creative Commons Attribution Non-Commercial License (https://creativecommons.org/licenses/by-nc/4.0) which permits unrestricted non-commercial use, distribution, and reproduction in any medium, provided the original work is properly cited.
We present a case of tension pneumocephalus that developed after ESS and repair of intraoperative CSF leakage. In this case, the onset of symptoms was delayed and the severity of symptoms was less compared to that in other cases of tension pneumocephalus. We also reviewed the related literature regarding the diagnosis and treatment approach of tension pneumocephalus.

\section{Case}

A 59-year-old male presented to the emergency department with profound lethargy, progressive headache, personality changes and mood swings. The symptoms had developed since the last 1 week. The patient had a history of diabetes and depressive disorder, which was diagnosed recently based on the above mentioned symptoms; and he had undergone ESS 6 weeks ago. He had visited our outpatient clinic with a 
2-month history of nasal obstruction and epistaxis. He had already been diagnosed as having chronic rhinosinusitis and nasal polyps, but there was no response to medical treatment. In the contrast computed tomography (CT) scan of his paranasal sinuses, there was a soft tissue mass that had completely filled the right maxillary sinus and was extending into the nasal cavity with widening of the maxillary ostium, the ethmoidal infundibulum, and lifting of the ethmomaxillary plate. This mass was diagnosed as inverted papilloma (Fig. 1). He underwent right endoscopic medial maxillectomy under general anesthesia and the diagnosis of inverted papilloma was confirmed by frozen biopsy. Intraoperatively, it was noted that the mass was penetrating into the anterior skull base and there was a $1.5-\mathrm{cm}$ dural defect resulting in CSF leakage following the surgery. The defect was repaired using an underlay technique with the inferior turbinate mucosal flap, and the septal cartilage was sealed with a fibrin sealant Tissucol Duo Quick ${ }^{\circledR}$ (Baxter AG, Vienna, Austria). The lumbar drain was maintained for 3 days postoperatively. He was discharged from the hospital on the seventh day after surgery. During the followup period, 3 days before the visiting the emergency room, he complained of non-locaized mild headache and mild lethar-

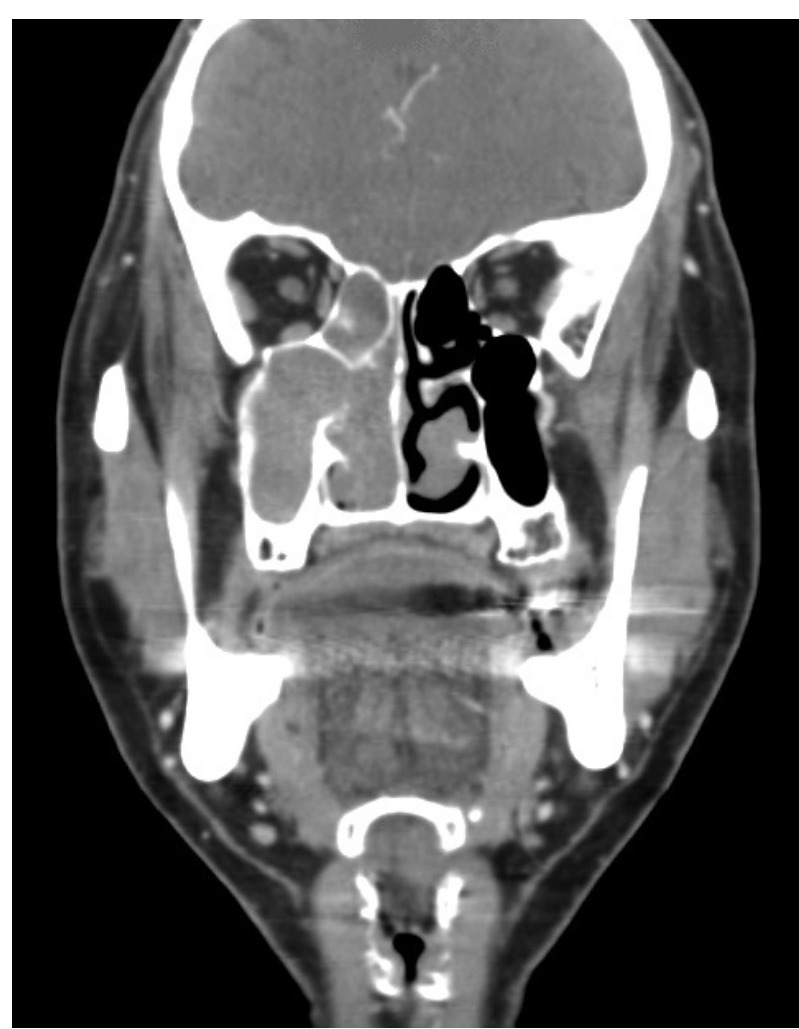

Fig. 1. In the CT scan of paranasal sinuses, the right maxillary sinus was filled with a heterogeneous soft tissue mass. The mass was extending into the nasal cavity with widening of the maxillary ostium. gy. Also, no obvious CSF leakage was detected on nasal endoscopy (Fig. 2).

In the emergency room, he was found to be confused, but was following commands, and was oriented to person and place. On neurologic examination, his Glasgow Coma Scale score was 15 . He showed normal pupillary reflexes, normal motor and sensory functions in all 4 extremities, normal deep tendon reflexes. A non-contrast CT scan of his brain was performed, and it showed significant air collection in the right frontal area and also a midline shift (Fig. 3). He was diagnosed with a tension pneumocephalus and referred to the neurosurgery department. Then, he underwent a bifrontal craniotomy for tension pneumocephalus. During the operation, we found adhesions between the nasal mucosa and dura mater, but there was no defect between nasal mucosa and dura and no CSF leakage. After detaching these adhesions, duroplasty and cranioplasty were performed. Postoperative conservative treatment was applied, including bed rest, meningitis prophylaxis, maintenance of extraventricular drainage. In the follow-up CT taken at 2 weeks after the surgery, resolution of tension pneumocephalus was observed (Fig. 4). His condition was stable and he showed a normal mental status, not confused. He was discharged 14 days after the surgery. In an endoscopic examination performed in the 2nd month, there was no skull base defect or CSF leakage (Fig. 5). The patient did not have any complaints or symptoms for 6 months after the surgery.

\section{Discussion}

Pneumocephalus is a rare complication, and it is defined as

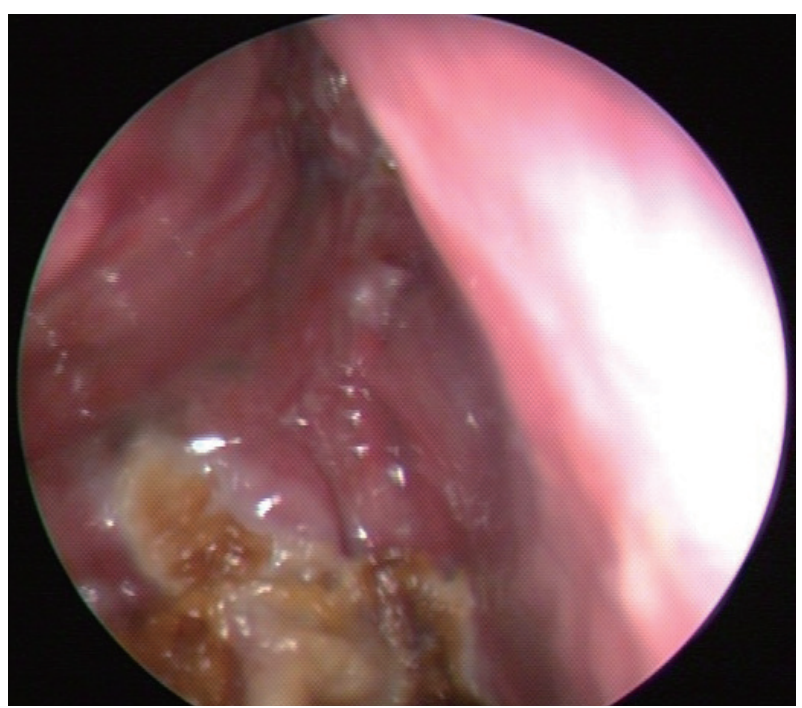

Fig. 2. Endoscopic finding of the dural repair site. There was no cerebrospinal fluid leakage at postoperative 6 weeks. 

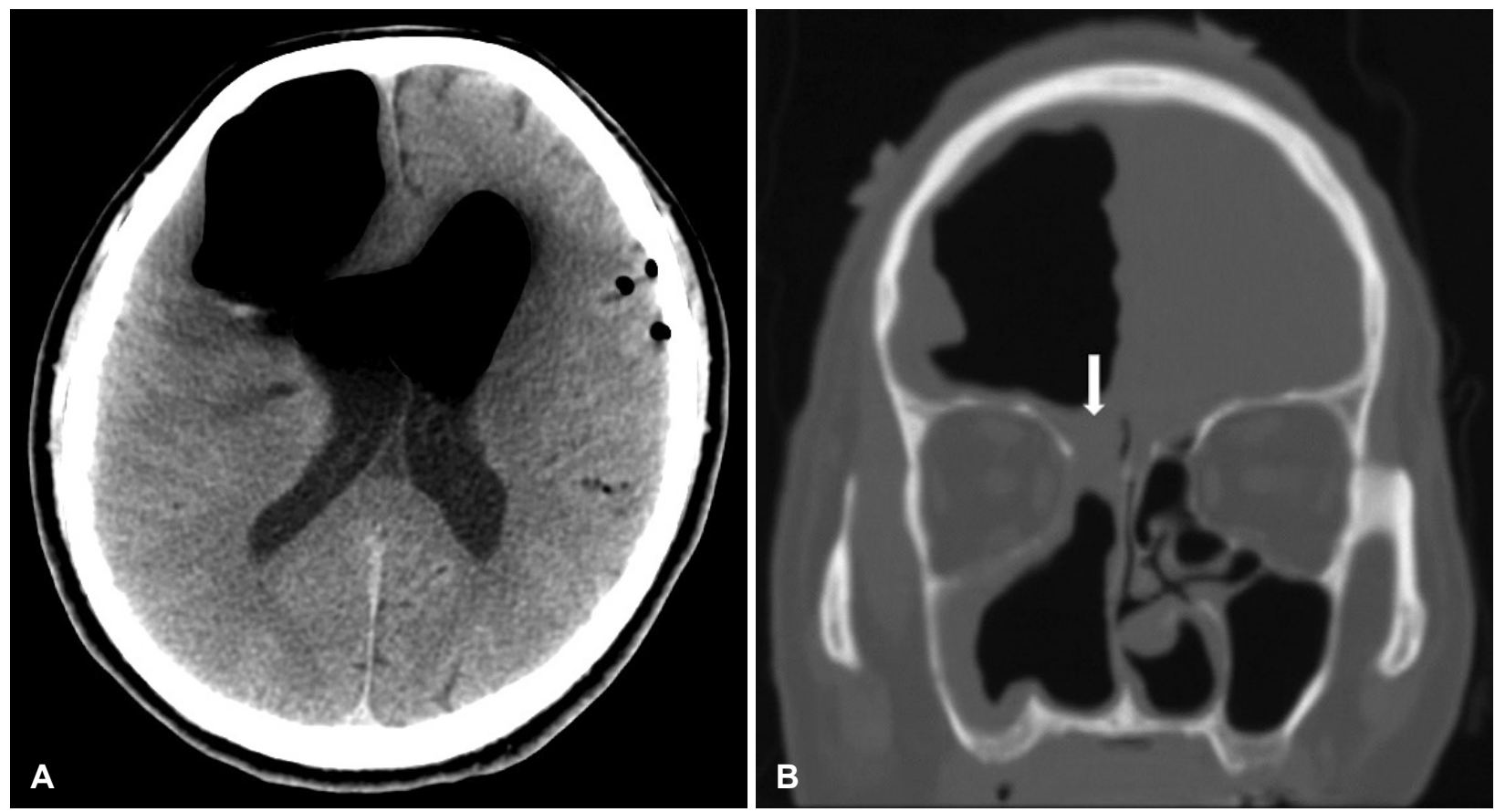

Fig. 3. (A) Axial and (B) coronal CT scans of paranasal sinuses showed a large amount of air in the right frontal area at 6 weeks after endoscopic sinus surgery for the inverted papilloma and possible skull base defect causing intraoperative cerebrospinal fluid leakage and pneumocephalus (arrow).

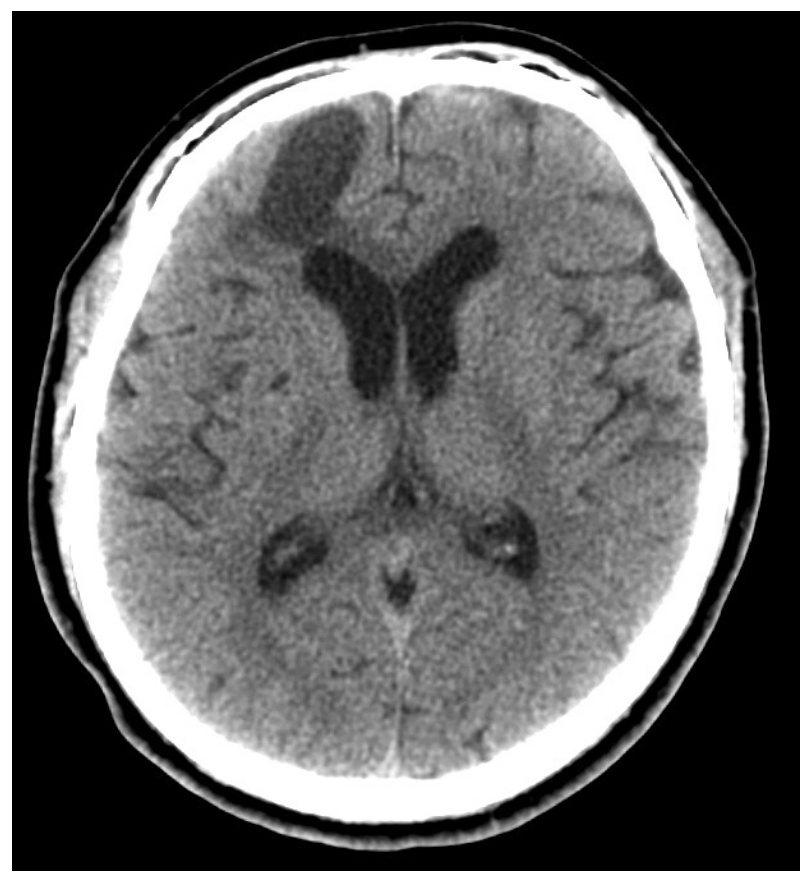

Fig. 4. The postoperative brain CT scan at 2 weeks showed a resolved tension pneumocephalus.

the presence of air in the cranial cavity. It can occur as a result of head trauma $(73.9 \%)$, neoplasm $(12.9 \%)$, infection $(8.8 \%)$, and surgery $(3.7 \%)^{6}{ }^{6}$ Surgery is a rare cause of pneumocephalus. Rhinologic surgeries have been reported to cause pneumocephalus, including ESS, intranasal ethmoidectomy, nasal

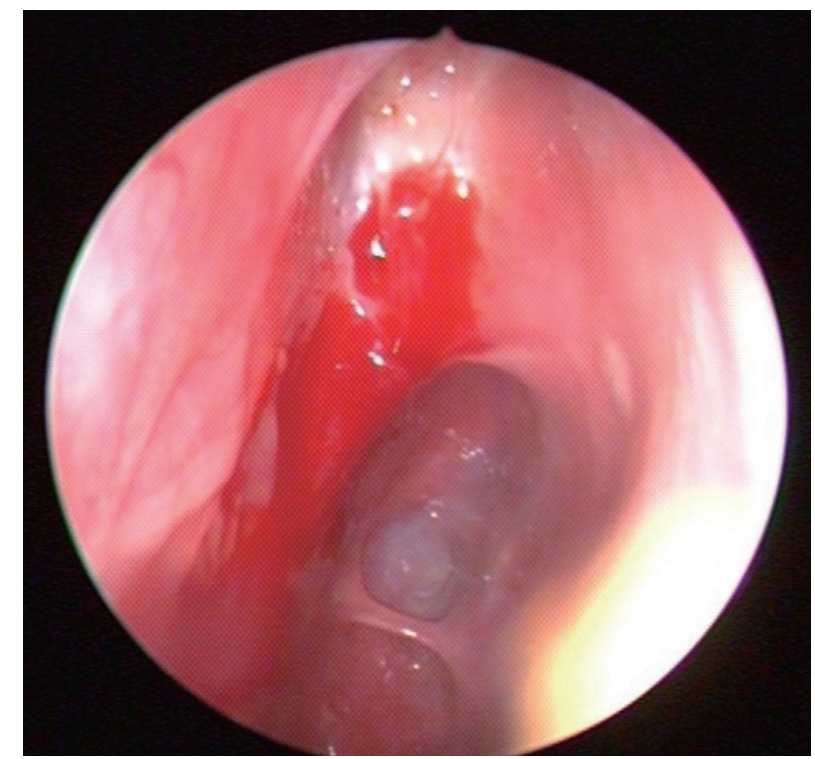

Fig. 5. The endoscopic finding of the repair site in the 2 nd month after duroplasty. There was no cerebrospinal fluid leakage.

septoplasty, and turbinate resection. ${ }^{7)}$ Pneumocephalus usually resolves spontaneously and progresses asymptomatically. But if the air continues to accumulate, the increased positive pressure in the cranium causes the mass effect, which is called tension pneumocephalus. Headache and altered mental status are the most common symptoms, but other symptoms can also develop, including visual disturbances, dizziness, and per- 
sonality changes. The severity of symptoms depends on the amount of air in the cranial cavity. There are two mechanisms that explain the development of pneumocephalus; the 'ballvalve mechanism' and the 'inverted-soda-bottle effect.' The 'ball-valve mechanism' occurs when elevated upper airway pressures, particularly when the patient coughs, sneezes or blows the nose, force air intracranially through a bony defect; the air is subsequently trapped by the filling of the defect with the surrounding soft tissue. ${ }^{7)}$ Significant resistance to the outflow of air leads to tension pneumocephalus. ${ }^{4)}$ In the 'inverted-soda-bottle effect,' drainage of the CSF leads to a negative intracranial pressure gradient which is relieved by the influx of air. The amount of air is independent of the size of the defect, but smaller defects are more easily sealed by blood clots or granulation, allowing for gradual reabsorption and spontaneous resolution of the pneumocephalus. ${ }^{4}$ )

In our case, the defect was repaired using an underlay technique with the inferior turbinate mucosal flap. And this flap was placed on the intracranial (proximal) side of the defect between the dura meter and bone. The nasal mucosa was directly attached to the dura mater but there was no defect between these two structures. We thought that there might be tiny intramucosal canal formation between mucosal flap and nasal cavity mucosa and small amounts of air slowly accumulated intracranially through this tiny defect. The air was trapped due to the 'ball-valve mechanism' without nasal blowing. Another possible cause is lumbar drainage. We performed lumbar drainage and it could leads tension pneumocephalus by the 'Inverted-soda-bottle effect.'

Tension pneumocephalus usually manifests after a few hours. DelGaudio and Ingley ${ }^{1)}$ reported 8 cases of pneumocephalus occurring within 1 week after ESS, and Whitmore, et al. ${ }^{7)}$ discussed 1 case of tension pneumocephalus that manifested 3 days after ESS. The case reported in this study is rare since tension pneumocephalus manifested at 6 weeks after ESS without CSF leakage.

A definitive diagnosis of pneumochepalus is made by a brain CT, although nasal endoscopy may also provide timely and valuable information regarding the size, location, and possible CSF leakage associated with the bony defect. ${ }^{7)}$ Our case was unusual due to several reasons; 1) it was caused by ESS and there was no CSF leakage, 2) there was a late onset of symptoms and gradually worsening of the symptoms, 3) there was no neurological deficit or altered mental status except personality change and mood swing during 6 weeks, 4) there was no defect between the nasal mucosa and dura in the opera- tive findings.

For the treatment of pneumocephalus that develops after rhinologic surgery, the repair of skull base defect or CSF leakage is the most important. Decompression is rarely performed in cases of simple pneumocephalus, because the intracranial air is gradually reabsorbed after repairing the skull base defect. But, in cases of tension pneumocophalus, neurosurgical decompression is performed more frequently, particularly when its evolution is rapid and life-threatening. ${ }^{7)}$ Toung, et al. ${ }^{8}$ treated their patients by craniotomy, and Bouzarth, et al. ${ }^{9)}$ described the use of a percutaneous catheter with negative pressure to remove the intracranial air for decompression. Failure of repeated endonasal or other extracranial approaches in abolishing the CSF leakage is an indication for intracranial exploration and treatment. ${ }^{10)}$

For prevent pneumocephalus after CSF leakage repair surgery, clinicians should always maintain a high index of suspicion for pneumocephalus especially with hadaches and abnormal mental status. Careful endoscopic exploration should be performed to check a remained intermittent or constant CSF leak. And with clinical suspicion, Brain CT should be performed to diagnose and allow immediate management of tension pneumocephalus. Interestingly, the case in this study is rare since tension pneumocephalus manifested at 6 weeks after ESS without CSF leakage and there was no neurological deficit or altered mental status except personality change and mood swing during 6 weeks. So clinicians should also consider 'delayed' tension pneumocephalus.

In conclusion, tension pneumocephalus is a rare complication after ESS, and it should be considered in all patients who not only show an altered mental status, but also mild neurological deficits or headache, and lethargy as in this case. Without clinical suspicion, it is difficult to diagnose tension pneumocephalus. Even if the patient does not show obvious neurological symptoms and the nasal endoscopic examination is normal, a careful clinical suspicion could help to detect tension pneumocephalus early in patients who have undergone ESS.

\section{Acknowledgments}

This research was supported by the Basic Science Research Program through the National Research Foundation of Korea (NRF) funded by the Ministry of Education (NRF-2016R1D1A1B01- 012705, NRF-2016R1A5A2012284).

\section{Author Contribution}

Conceptualization: Jin Kook Kim. Data curation: Hansol Kim, Taesik Jung. Formal analysis: Hansol Kim, Taesik Jung, Jin Kook Kim. Methodology: Jin Kook Kim. Project administration: Joon Yong Park, Jin Kook Kim. Supervision: Jin Kook Kim. Visualiza- 
tion: Hansol Kim, Taesik Jung. Writing—original draft: Joon Yong Park. Writing — review \& editing: Jin Kook Kim.

\section{ORCIDs}

Jin Kook Kim

Joon Yong Park

Hansol Kim

Taesik Jung

https://orcid.org/0000-0003-4245-6252

https://orcid.org/0000-0001-6003-9474

https://orcid.org/0000-0002-3650-4441

https://orcid.org/0000-0002-1161-6156

\section{REFERENCES}

1) DelGaudio JM, Ingley AP. Treatment of pneumocephalus after endoscopic sinus and microscopic skull base surgery. Am J Otolaryngol 2010;31(4):226-30.

2) May M, Levine HL, Mester SJ, Schaitkin B. Complications of endoscopic sinus surgery: Analysis of 2108 patients--incidence and prevention. Laryngoscope 1994;104(9):1080-3.

3) Shaikh N, Masood I, Hanssens Y, Louon A, Hafiz A. Tension pneumocephalus as complication of burr-hole drainage of chronic subdural hematoma: A case report. Surg Neurol Int 2010;1:27.

4) Schirmer CM, Heilman CB, Bhardwaj A. Pneumocephalus: Case illustrations and review. Neurocrit Care 2010;13(1):152-8.

5) Aksoy F, Dogan R, Ozturan O, Tuğrul S, Yıldırım YS. Tension pneumocephalus: An extremely small defect leading to an extremely serious problem. Am J Otolaryngol 2013;34(6):749-52.

6) Markham JW. The clinical features of pneumocephalus based upon a survey of 284 cases with report of 11 additional cases. Acta Neurochir (Wien) 1967;16(1):1-78.

7) Whitmore RG, Bonhomme G, Balcer LJ, Palmer JN. Tension pneumocephalus after endoscopic sinus surgery: Case report of repair and management in absence of obvious skull base defect. Ear Nose Throat J 2008;87(2):96-9.

8) Toung T, Donham RT, Lehner A, Alano J, Campbell J. Tension pneumocephalus after posterior fossa craniotomy: Report of four additional cases and review of postoperative pneumocephalus. Neurosurgery 1983;12(2):164-8.

9) Bouzarth WF, Hash CJ, Lindermuth JR. Tension pneumocephalus following surgery for subdural hematoma. J Trauma 1980;20(6): 460-3.

10) Burkey BB, Gerek M, Day T. Repair of the persistent cerebrospinal fluid leak with the radial forearm free fascial flap. Laryngoscope 1999;109(6):1003-6. 